\title{
COMPREENSÕES DE PROFESSORES QUE ATUAM NA PÓS-GRADUAÇÃO STRICTO-SENSU SOBRE PROFESSOR REFLEXIVO E PROFESSOR PESQUISADOR
}

\author{
WHAT STRICTO SENSU GRADUATE PROGRAM TEACHERS \\ UNDERSTAND BY \\ THE REFLECTIVE TEACHER AND RESEARCHER TEACHER
}

\author{
Recebido em: 16/10/2012 Aprovado em: 13/01/2013 \\ Avaliado pelo sistema double blind review \\ Editora Científica: Manolita Correia Lima
}

\author{
FERNANDA KREUZBERG fernandakreuzberg@gmail.com \\ RITA BUZZI RAUSCH \\ UNIVERSIDADE REGIONAL DE BLUMENAU
}

\begin{abstract}
RESUMO
O objetivo desta pesquisa foi analisar a compreensão de professores que atuam no stricto-sensu sobre professor reflexivo e professor pesquisador. Com caráter descritivo, de levantamento e qualitativo, foram feitas entrevistas com dez professores de um Programa de Pós-Graduação em Ciências Contábeis, que atuaram no último trimestre de 20II. Na compreensão da maioria dos entrevistados, o professor pesquisador não se preocupa somente com o ensino, mas também com a pesquisa, para que ocorra uma evolução do conhecimento. Este assume um papel de mediador e não apenas de transmissor do conhecimento. Quanto à compreensão de professor reflexivo, a maioria dos entrevistados destacou ser aquele capaz de regular a sua ação e apresentar um método sistematizado de pensar, mas não necessariamente um pensar crítico sobre a docência. Percebe-se que ocorre uma aproximação dos conceitos de professor pesquisador e reflexivo na compreensão dos professores investigados, entretanto a predominância do olhar concentrou-se mais sobre as atitudes dos alunos do que na sua própria docência. Percebeu-se também, em alguns momentos, a compreensão de professor pesquisador focado meramente à pesquisa, e não necessariamente à pesquisa sobre a docência, bem como a compreensão de professor reflexivo, pouco voltada à relação teoria e prática na docência.

Palavras-chave: professor pesquisador; professor reflexivo; docência; stricto-sensu.
\end{abstract}

\begin{abstract}
The objective of this research was to analyze the understanding of graduate degree teachers regarding the reflective teacher and researcher teacher. Interviews of a descriptive and qualitative nature were conducted with 10 teachers from a graduate Accounting degree who taught in the last quarter of 2011. The majority respondents understand the researcher teacher as not only concerned with teaching, but also with research, in order for knowledge to evolve. The researcher teacher assumes the role of a mediator in addition to being a passer-on of knowledge. Reflective teachers were understood as those able to regulate their actions and present a systematic method of thinking, but not necessarily a critical thinking about teaching. It was observed that there is an approximation of the concepts of researcher and reflective teachers among the teachers surveyed, however of them focusing on their students attitudes, than in their own vision of teaching. The researcher teacher was also occasionally thought to be too merely focused on research that was not necessarily research on teaching, while reflective teachers were understood to sometimes lack an emphasis on the relationship between theory and practice in teaching.

Keywords: researcher teacher; reflective teacher; teaching; graduate degree.
\end{abstract}




\section{INTRODUÇÃO}

Atualmente, investigar a formação e atuação do professor e promover reflexões acerca destes processos representam grandes desafios a serem enfrentados. Fontana (2006) defende que a formação do professor pesquisador e do professor reflexivo assume um caráter de qualificação da docência na atuação crítica em uma perspectiva transformadora da prática educativa.

Constata-se que o aluno dos dias de hoje mudou, em aspectos de inteligência e habilidades; dessa forma, é necessário que ocorra uma mudança também no processo de construção do seu conhecimento. Conforme Miranda (2008), essa mudança configura-se também no trabalho do professor, ressignificando a maneira de orientar a aprendizagem do aluno, bem como a construção do seu próprio saber docente.

A prática reflexiva proporciona a compreensão, o que de certa forma acarreta na produção do saber, bem como num conhecimento mais bem elaborado. A formação docente de qualidade apresenta como indicadores a busca de uma formação tanto teórica quanto prática, o processo coletivo de investigação e reflexão, sendo isso possível pela integração da pesquisa e da reflexividade no processo de docência.

Um dos pontos mais instigantes para o desenvolvimento desta pesquisa foi uma das constatações, encontradas por Lüdke (2008), quanto à prática de pesquisa pelos professores ter sido apontada como não importante por professores formadores de futuros docentes. Nesta pesquisa, o componente pesquisa não foi apontado como necessário para a formação do futuro mestre. Essa ausência foi surpreendente, o que motivou a escolha por esta pesquisa.

No Brasil, a formação de professores para atuar na educação superior ocorre principalmente via programas de pós-graduação stricto-sensu. Portanto, os professores que atuam no stricto-sensu, em sua maioria, são também formadores de professores. Conforme Castanho e Freitas (2006), o papel do professor no ensino superior, incluindo aqui o professor de pósgraduação, requer uma postura ativa, crítica, política e ética. Para isto, faz-se necessário que seja um professor reflexivo e pesquisador. 
Diante disso, surge a seguinte questão de pesquisa: Qual a compreensão de professores de um Programa de Pós-Graduação stricto sensu sobre professor reflexivo e professor pesquisador? O objetivo da pesquisa foi analisar a compreensão de professores de um Programa de Pós Graduação de Ciências Contábeis sobre professor pesquisador e professor reflexivo.

O processo de reflexividade na docência é defendido principalmente por Schön (2000), Sá-Chaves (2000, 2002) e Alarcão (2005). Esta última autora difundiu a reflexividade bem como a criação de uma escola reflexiva em Portugal e no Brasil. Para tais autores, a transformação da prática do professor não ocorre apenas pelo acúmulo teórico de transmissão de informações, nem por uma ação rotineira, mas sim pela reflexividade do professor. Já a perspectiva do professor pesquisador é defendida especialmente por Zeichner (1998); André (2008) e Lüdke (2008), que abordam a pesquisa como um elemento essencial na formação e atuação docente.

\section{PROFESSOR PESQUISADOR}

Desde 1975, a expressão professor pesquisador vem se expandindo consideravelmente na literatura internacional acerca da profissão docente, principalmente, pela divulgação das ideias de Stenhouse (I975), em que considera a necessidade de o professor ser um artista, criando diversas técnicas de ensino e aprendizagem. Para isto torna-se necessário a investigação de sua própria prática docente.

No Brasil, "a formação de professores já admite a importância da pesquisa na preparação e no trabalho do professor" (LÜDKE, 2008, p. 30). Porém, conforme Nunes (2007), essa implementação na prática apresenta grandes desafios. Como exemplos, a carga de trabalho precisa dos professores, os baixos incentivos à profissão de professor, o pouco desenvolvimento de pesquisa pelos professores bem como a ausência de agentes financiadores.

Para Charlot (2002, p. 9I), "O papel da pesquisa é forjar instrumentos, ferramentas para melhor entender o que está acontecendo na sala de aula; é criar inteligibilidade para melhor entender o que está acontecendo ali”. Neste sentido, a definição de professor pesquisador passa a ser entendida como o profissional que investiga seu contexto docente de forma 
sistematizada. Borg (2010) apresenta vertentes de pesquisa dos professores, sendo eles: a investigação social, o conhecimento nas comunidades, como uma investigação da prática docente. A primeira parte do pressuposto de pesquisa-ação, como forma de promover mudanças na sociedade. $\mathrm{Na}$ segunda vertente, investigam-se formas de melhorar as escolas e também as salas de aula. Por fim, na investigação da prática, o professor é visto como um pesquisador que desenvolve conhecimento sobre sua atuação docente.

Zeichner (1998) discute questões de poder, privilégio, voz e status na pesquisa educacional, bem como a necessidade de eliminar a separação que atualmente existe entre o mundo dos professores-pesquisadores e o mundo dos pesquisadores-acadêmicos. O autor conclui que no momento muitos professores mencionam que a pesquisa educacional realizada na academia é irrelevante para suas vidas nas escolas. É por isso que grande parte dos professores não procura a pesquisa educacional para instruir e melhorar suas práticas docentes.

De acordo com Lüdke (2008), vale ressaltar a importância do contato do aluno com a teoria, pois, diante disso, o aluno busca analisar os seus dados de pesquisa, bem como promover a criticidade em seus estudos. Para André (2008, p. 60), "o movimento em prol do professor pesquisador tem o mérito de valorizar o papel social do professor como agente de mudança e produtor de conhecimento".

Para Borg (2010), ocorre uma distinção entre reflexão e pesquisa, ou seja, enquanto que a pesquisa do professor visa a ser reflexiva, a reflexão sobre a própria prática não se constitui na pesquisa do professor. Nos Estados Unidos, Schön (2000) introduziu a prática reflexiva, que atualmente é vista como fundamental para a pesquisa dos professores, e que utiliza como argumento que os profissionais não são meramente técnicos, mas sim que desenvolvem seu papel como investigadores. Dessa forma, a pesquisa dos professores passa a ser um elemento reflexivo também. Por isso, discutese hoje a necessidade de se formarem professores reflexivos e também pesquisadores. 


\section{PROFESSOR REFLEXIVO}

Na década de I980, ocorreu o movimento em favor do professor reflexivo, motivado principalmente pelas ideias de Dewey e Donald Schön, que atribuiriam à reflexão uma prática social. Conforme Fontana (2006, p. 66), Schön defende a percepção de que o professor reflexivo "[...] pensa sobre o que faz ao se deparar com situações de incertezas e conflitos”, investigando dessa forma a sua própria ação.

De acordo com Schön (2000), um professor reflexivo deve permitir ser surpreendido com o que o aluno faz, de modo que aprenda com ele, e, no momento em que acontece a sua própria reflexão, reformula-se a sua docência buscando novos significados e sentidos sobre seu trabalho. Para Monteiro (2008, p. 43), ser um profissional reflexivo significa "apropriar-se de teorias que analisem o fenômeno em estudo, tomar consciência delas e debruçar-se sobre o conjunto de sua ação, refletindo sobre seu ensino e sobre as condições sociais nas quais se está inserido”. Para Alarcão (2005, p. 4I), o professor reflexivo se baseia "na consciência da capacidade de pensamento e reflexão que caracteriza o ser humano como criativo e não como mero reprodutor de ideias e práticas que lhe são exteriores”.

Conforme Schön (2000), as noções essenciais para um processo de reflexividade pode ser denominada pela praxiologia para a reflexão, em que existe o conhecimento na ação (o conhecimento na execução), a reflexão na ação (pensar sobre o que fazer no momento em que se está atuando). Na praxiologia para a reflexão existe a reflexão sobre a ação (reconstrução da ação de forma mental para a posterior análise) e, por último, a reflexão sobre a reflexão na ação (realização da crítica após a ação). Desta forma, para Schön, os profissionais reflexivos refletem "na", "sobre" e "para a ação".

O professor reflexivo parte de um pressuposto de reflexão e construção de conhecimentos por meio do pensamento sobre a sua prática (ALARCÃO, 2005). Conforme Monteiro (2008), ser um professor reflexivo é uma exigência cada vez mais pertinente neste mundo em constante transformação, salientando também que os professores devem estar preparados para este ambiente de mudança. 


\section{PROCEDIMENTOS METODOLÓGICOS}

Esta pesquisa caracteriza-se como descritiva, de levantamento e qualitativa. A escolha da população da pesquisa compreende os professores integrantes do Programa de Pós-Graduação em Ciências Contábeis de uma universidade de Santa Catarina. Os participantes da pesquisa foram io (dez) professores, conforme caracterização apresentada no Quadro I.

Quadro 1 Caracterização dos sujeitos da pesquisa

\begin{tabular}{|c|c|c|c|c|}
\hline Sujeitos & Formação & Linha de Pesquisa & $\begin{array}{l}\text { Tempo de } \\
\text { atuação na } \\
\text { docência }\end{array}$ & $\begin{array}{l}\text { Tempo de } \\
\text { atuação no } \\
\text { stricto-sensu }\end{array}$ \\
\hline Professor A & $\begin{array}{l}\text { Doutor em Ciências Contábeis } \\
\text { e Administração; Mestre em } \\
\text { Ciências Contábeis; Especialista } \\
\text { em Contabilidade Gerencial e } \\
\text { Finanças; Graduação em Ciências } \\
\text { Contábeis }\end{array}$ & $\begin{array}{l}\text { Controladoria e } \\
\text { Contabilidade } \\
\text { Internacional }\end{array}$ & 13 anos & 1 ano \\
\hline Professor B & $\begin{array}{l}\text { Doutor em Controladoria e } \\
\text { Contabilidade; Mestre em } \\
\text { Controladoria e Contabilidade; } \\
\text { Graduação em Ciências } \\
\text { Contábeis }\end{array}$ & $\begin{array}{l}\text { Planejamento, } \\
\text { controle } \\
\text { organizacional } \\
\text { e Contabilidade } \\
\text { Financeira }\end{array}$ & 14 anos & 8 anos \\
\hline Professor C & $\begin{array}{l}\text { Doutor em Ciências Contábeis } \\
\text { e Administração; Mestre em } \\
\text { Ciências Contábeis; Especialista } \\
\text { em Contabilidade Financeira } \\
\text { e Auditoria; Graduação em } \\
\text { Ciências Contábeis }\end{array}$ & $\begin{array}{l}\text { Auditoria e } \\
\text { Controles Internos }\end{array}$ & 9 anos & 1 ano \\
\hline Professor D & $\begin{array}{l}\text { Doutor em Contabilidade; } \\
\text { Mestre em Ciências } \\
\text { Contábeis; Especialização em } \\
\text { Administração; Graduação em } \\
\text { Ciências Contábeis; Graduação } \\
\text { em Administração }\end{array}$ & $\begin{array}{l}\text { Contabilidade } \\
\text { Financeira }\end{array}$ & 17 anos & 8 anos \\
\hline Professor E & $\begin{array}{l}\text { Doutora em Educação; Mestre } \\
\text { em Educação; Especialização em } \\
\text { Alfabetização; Graduação em } \\
\text { Pedagogia }\end{array}$ & $\begin{array}{l}\text { Formação e atuação } \\
\text { docente }\end{array}$ & 21 anos & 6 anos \\
\hline
\end{tabular}


PROFESSOR REFLEXIVO E PROFESSOR PESQUISADOR

\begin{tabular}{|c|c|c|c|c|}
\hline Sujeitos & Formação & Linha de Pesquisa & $\begin{array}{l}\text { Tempo de } \\
\text { atuação na } \\
\text { docência }\end{array}$ & $\begin{array}{l}\text { Tempo de } \\
\text { atuação no } \\
\text { stricto-sensu }\end{array}$ \\
\hline Professor $F$ & $\begin{array}{l}\text { Doutor em Controladoria e } \\
\text { Contabilidade; Mestre em } \\
\text { Engenharia de Produção; } \\
\text { Mestre em Controladoria e } \\
\text { Contabilidade; Graduação em } \\
\text { Ciências Contábeis }\end{array}$ & $\begin{array}{l}\text { Controles de gestão } \\
\text { e Planejamento } \\
\text { Organizacional }\end{array}$ & 11 anos & 5 anos \\
\hline Professor G & $\begin{array}{l}\text { Doutor em Controladoria e } \\
\text { Contabilidade; Mestre em } \\
\text { Controladoria e Contabilidade; } \\
\text { Graduação em Ciências } \\
\text { Econômicas }\end{array}$ & $\begin{array}{l}\text { Contabilidade } \\
\text { Gerencial }\end{array}$ & 10 anos & 10 anos \\
\hline Professor $\mathrm{H}$ & $\begin{array}{l}\text { Pós-Doutor em Contabilometria; } \\
\text { Pós-Doutor em Matemática; } \\
\text { Doutor em Engenharia de } \\
\text { Produção; Mestre em Engenharia } \\
\text { de Produção; Graduação em } \\
\text { Matemática }\end{array}$ & $\begin{array}{l}\text { Planejamento } \\
\text { e controle } \\
\text { organizacional }\end{array}$ & 17 anos & 7 anos \\
\hline Professor I & $\begin{array}{l}\text { Doutora em Controladoria } \\
\text { e Contabilidade; Mestre em } \\
\text { Ciências Contábeis; Mestrado em } \\
\text { Administração; Especialização } \\
\text { em Ciências Contábeis; } \\
\text { Graduação em Ciências } \\
\text { Contábeis }\end{array}$ & Controladoria & 29 anos & 8 anos \\
\hline Professor J & $\begin{array}{l}\text { Doutor em Controladoria e } \\
\text { Contabilidade; Mestre em } \\
\text { Controladoria e Contabilidade; } \\
\text { Graduação em Economia; } \\
\text { Graduação em Ciências } \\
\text { Contábeis }\end{array}$ & $\begin{array}{l}\text { Gerenciamento de } \\
\text { risco de mercado; } \\
\text { Contabilidade } \\
\text { Financeira }\end{array}$ & 35 anos & 11 anos \\
\hline
\end{tabular}

O estudo foi desenvolvido por meio de entrevistas. As entrevistas foram gravadas, transcritas e analisadas, sempre respeitando devidamente os princípios éticos da pesquisa científica. Os professores foram questionados quanto ao seu entendimento sobre professor pesquisador, bem como as práticas por eles adotadas na docência, que evidenciam a perspectiva do professor pesquisador. Em seguida, foram questionados sobre o entendimento de professor reflexivo, assim como as práticas por eles adotadas na docência, que evidenciam a perspectiva de professor reflexivo. 
A descrição e análise dos dados coletados foram realizadas, inicialmente, por meio da análise de conteúdo das entrevistas feitas com os professores do Programa de Pós-Graduação em Ciências Contábeis. Para Freitas e Janissek (2000, p. 37), "a análise de conteúdo pode ser usada para analisar em profundidade cada expressão específica de uma pessoa ou grupo envolvido num debate".

\section{COMPREENSÕES DE PROFESSOR PESQUISADOR}

Primeiramente, os professores foram questionados quanto à sua percepção de professor pesquisador. Observa-se que eles não apresentaram um conceito de professor pesquisador bem definido. Ao analisar a compreensão dos professores, identificaram-se diversas formas de entendimento que foram categorizadas em quatro vertentes: a) o professor que somente realiza pesquisa; b) o professor que socializa aos seus alunos as investigações que envolvem sua linha de pesquisa; c) o professor que permite que os alunos realizem pesquisa d) o professor preocupado com a evolução do conhecimento, conforme apresentado na Figura I.

Figura 1 Categorias identificadas de professor pesquisador

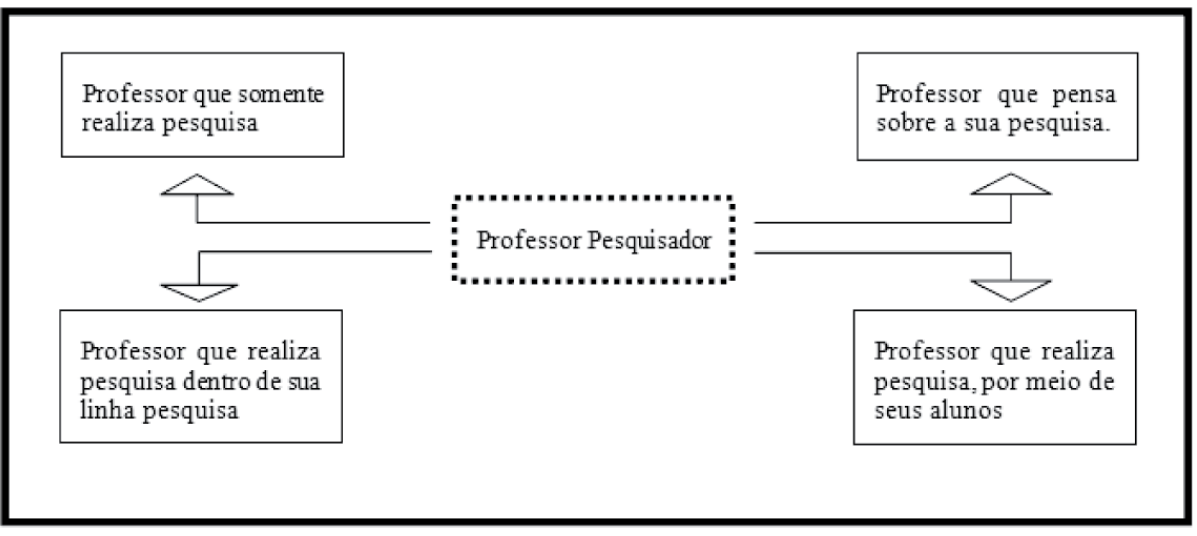

No contexto investigado, surgiram definições sobre o que é ser um professor pesquisador, sob uma perspectiva do professor que somente realiza pesquisa, reconhecido na literatura como pesquisador professor. Dessa 
forma, o professor pesquisador "é aquele que dedica uma parcela relevante de seu tempo às atividades de pesquisa e ao desenvolvimento de produção cientifica” (PROFESSOR G).

De acordo com a percepção do Professor J, professor pesquisador "é o professor que faz pesquisa. Na verdade tem aquele há o professor que dá aula e aquele que faz pesquisa. Aqui no Brasil, nós precisamos dar aula e fazer pesquisa". O mesmo ainda complementa que "seria melhor uma dedicação total à pesquisa. Mas, no atual contexto brasileiro, isso se torna inviável, surge assim uma exigência, que além de sermos professores devemos ser pesquisadores.” Nunes (2007) acrescenta que as principais dificuldades encontradas pelos pesquisadores vão desde a própria carga de trabalho do professor, até aos escassos incentivos e à carência de agentes financiadores.

Outra compreensão de professor pesquisador identificada na pesquisa caracteriza-se como aquela em que os professores socializam aos seus alunos as investigações que envolvem sua linha de pesquisa. Para um dos entrevistados, "o professor pesquisador tem o intuito de verificar problemáticas que ele acompanha no seu dia a dia e a partir disso contribuir com base em teorias de sustentações para responderem esses problemas, relacionados ao seu ambiente profissional e acadêmico" (PROFESSOR C). Conforme André (2008), o professor qualifica a sua prática pedagógica, de modo que favoreça a relação teoria e prática e a aprendizagem dos alunos. Conforme os resultados encontrados na pesquisa de Fontana (2006), os alunos ressaltam a qualidade da atuação do professor-pesquisador em sala de aula pela articulação que faz com a pesquisa que desenvolve e pela utilização de pesquisas atualizadas na área da disciplina que ministra.

Analisando sob a óptica da pesquisa realizada pelos alunos, vale destacar a compreensão do Professor $\mathrm{D}$, em que os professores adotam a prática de "incorporar o hábito de pesquisar entre os alunos, dando temas para eles, para que eles possam desenvolver alguns trabalhos em sala de aula e pesquisas mais organizadas, não só postar livros sobre o tema, mas buscar mais material”. André (2008) ressalta que trazer pesquisas recentes com abordagens de problemáticas que permitam o conhecimento aproxima o aluno com a realidade. Outro método adotado nas aulas 
É a pesquisa relacionada com a apresentação de seminários, essa prática estimula os alunos também a se envolver com a pesquisa, então o professor consegue incentivar os alunos a fazer pesquisa na prática, trazer o resultado dessa pesquisas para a sala de aula, apresentar os resultados desta pesquisa, para os demais colegas em sala (PROFESSSOR A).

Por sua vez, o Professor H apontou uma compreensão bastante diferente: "eu tive por muito tempo alunos bolsistas de iniciação científica, e que viam diariamente, não apenas o que eu fazia, mas com quem eu as fazia e eu acho que isso também é importante. Pesquisadores precisam de referências”. Lüdke (2008) em seu estudo destaca a importância das bolsas de iniciação científica já na graduação, pois possibilita aos alunos um acompanhamento do trabalho do professor na pesquisa, sendo este um fato que marca os estudantes para o restante da vida. Aprende-se a fazer pesquisa, fazendo pesquisa com pessoas mais experientes. A participação em pesquisas possibilita ao aluno uma melhor preparação para ser um futuro pesquisador. Ao encontro de Zeichner (I998), atualmente muitos professores sentem que a pesquisa educacional, que é conduzida pelos acadêmicos, é irrelevante para suas vidas nas escolas. Diante disso, uma grande parte dos professores não utiliza a pesquisa educacional como uma maneira de instruir e melhorar suas práticas.

Outra compreensão identificada nas entrevistas volta-se ao professor que pensa sobre o que está pesquisando. De acordo com a compreensão do Professor F, o professor pesquisador pode ter duas linhas, "tem aquele professor que alia ensino com pesquisa, ou seja, ele atua tanto na área de pesquisa quanto na área docente e que, por conta disso, ele tem certo comportamento de aliar sua pesquisa a técnica de ensino”.

Outra reflexão que a destcaram é que:

Professor pesquisador no meu entender é aquele que está preocupado não só com o ensinar, mas também com o pesquisar. O conhecimento que se transmite somente por meio do ensinamento, não é suficiente, porque se não houver pesquisa o conhecimento não evolui. A evolução do conhecimento se dá pela pesquisa, então a existência do professor pesquisador é fundamental porque senão não haveria uma evolução do conhecimento. Então o professor 
pesquisador é aquele que está preocupado com a evolução do pensamento (PROFESSOR A).

Pela definição do Professor A, é importante destacar que se trata do professor que produz conhecimento. Alarcão (2005) salienta a importância desse acompanhamento da evolução do conhecimento, que permite que ocorra um desenvolvimento da aprendizagem.

Para André (2008), o professor pesquisador visa à valorização do papel social do professor como um agente de mudança e produtor de conhecimento. Logo, “o professor pesquisador é muito mais aquele que faz o aluno chegar às respostas; acontece que nós temos professores que chegam com respostas prontas, quando ninguém fez alguma pergunta” (PROFEsSOR H). O mesmo professor apontou ainda que

O problema é que na universidade existe apenas pesquisa básica, ou seja, refazer coisas que já fizeram, precisa-se de coisas novas. Quando você tem uma questão nova, uma pergunta nova, uma técnica nova e, lógico, um método novo, pode-se gerar uma resposta. Afinal, para fazer pesquisa você necessita de três quesitos básicos: originalidade, contribuição científica de fato e não trivialidade (PROFESSOR H).

O professor pesquisador "tem uma postura não de transmissão de conhecimento, mas ele assume um papel de mediador, promovendo principalmente a construção do conhecimento ampliado, a partir da realidade do conhecimento que os alunos já têm" (Professor E). Conforme André (2008), a pesquisa tem uma função mediadora, ou seja, de colocar o aluno em contato com pesquisas mais atualizadas e incentivar os alunos a refazerem o processo de pesquisa, bem como discutirem os resultados e a metodologia.

Em se tratando das práticas adotadas na docência que evidenciam a perspectiva do professor pesquisador, o Professor E considera que "uma das primeiras coisas é organizar o trabalho disciplinar por meio de projetos de pesquisa, estabelecer uma intervenção pedagógica por meio da pesquisa”. Conforme André (2008), é necessário planejamento, bem como a elaboração de projetos para a elaboração de pesquisa. 
Uma das características que vale destacar sobre o professor pesquisador é que ele "instiga os alunos para a pesquisa. Ele não é aquele sujeito que vem com todas as suas respostas prontas, ele tende a fazer com que os alunos não somente tirem as dúvidas, mas fazer com que eles avancem no seu conhecimento" (PROFESSOR F). Isso possibilita que o aluno entre em contato com a teoria, o que é de inquestionável importância, pois, é por meio dela, que o aluno procura entender os dados de sua pesquisa. Conforme Fontana (2006), as principais práticas investigativas dos professores pesquisadores envolvem procedimentos de pesquisa tais como: pesquisa de campo, problematizações, levantamento de dados, elaboração de relatórios e fundamentação teórica.

\section{COMPREENSÕES DE PROFESSOR REFLEXIVO}

Os entrevistados também foram questionados quanto à sua compreensão de professor reflexivo. Este questionamento despertou surpresa em diversos entrevistados, por ser um termo pouco difundido no stricto-sensu. Devido à abrangência desta compreensão entre os professores, identificaram-se quatro categorias deste conceito: a) conceito indefinido de professor reflexivo; b) o professor que reflete sobre a teoria; c) o professor que reflete sobre a teoria que envolve sua prática docente, e d) aproximação dos conceitos de professor reflexivo e professor pesquisador, conforme a Figura 2.

Figura 2 Categorias identificadas de Professor Reflexivo

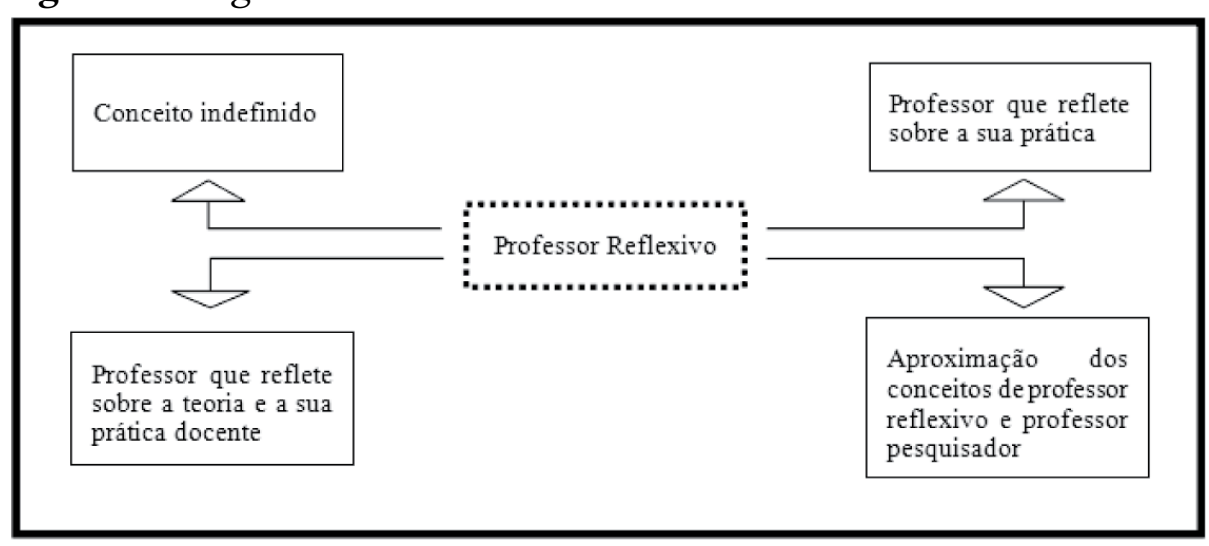


Num primeiro momento, em resposta ao questionamento de professor reflexivo, percebeu-se uma determinada surpresa pelos professores. Dessa forma, $70 \%$ dos entrevistados não souberam de forma imediata expressar algum conceito quanto a professor reflexivo, sendo que para alguns foi a primeira vez que escutaram algum questionamento sobre professor reflexivo (PROFESSOR D; PROFESSOR I; PROFESSOR B).

Outra abordagem encontrada no estudo identifica aquele professor que reflete sobre a teoria. Como resposta, obteve-se que professor reflexivo "é aquele que tem um método sistematizado de pensar suas questões" (PROFESSOR D). O mesmo justifica que "a pesquisa leva a refletir, porque estamos sempre preocupados em resolver problemas de pesquisa e para resolver um problema acaba-se fazendo reflexões, um pensamento organizado, sistematizado, não somente ideias sem uma sustentação teórica”.

Nesta direção, outro entrevistado mencionou o professor reflexivo como "aquele professor que busca refletir sobre o que ele vem pesquisando, o que ele vem aprendendo, sobre o que ele pode transmitir para os alunos. A reflexão também faz parte da construção do conhecimento” (PROFESSOR A). O entrevistado ainda complementa nesta mesma percepção que "ser um professor reflexivo é isso, é refletir sobre o conhecimento, sobre a pesquisa, sobre a produção de conhecimento, e fazer com que os alunos também consigam refletir sobre isso" (PROFEssOr A). A fala destes professores nos remetem a entender que para eles professor reflexivo é aquele que reflete sobre a teoria, muitas vezes a teoria que envolve suas pesquisas, mas não necessariamente a teoria que envolve sua docências.

Dessa forma, algumas das práticas, que evidenciam a presença do professor reflexivo, e estas diversas dinâmicas acabam por impactar na reflexão do próprio aluno também. Por exemplo, o seminário "força a pesquisa e depois o debate, reflexão com a turma, posicionamento crítico; isto está relacionado à questão reflexiva. Acho que as duas coisas são importantes e têm que andar juntas" (PROFESSOR A).

Alarcão (2005) salienta a importância desse acompanhamento da evolução do conhecimento, permitindo assim que ocorra um desenvolvimento da aprendizagem; isso pode ser explicado pela teoria da aprendizagem 
experiencial de David Kolb (1984). Por meio desta teoria, parte-se de um processo de compreensão da realidade, parte-se para a associação com a experiência e, então, para a reflexão da ação. Com base nisso, segue-se a descrição de uma prática que visa a esta integração teoria e prática e, por fim, o posicionamento crítico. O professor I, num primeiro momento, passa:

Mais conceitos e palavras-chave que eles vão investigar numa realidade empírica; a partir desta realidade empírica, eles vão para a sala de aula e apresentam essa realidade empírica e então fizemos análises em relação ao que vimos na teoria. Depois disso, são passados textos com uma profundidade maior e eles vão cotejar (buscar) aquela realidade empírica com a realidade teórica que se analisou. Então é um momento que eu trago textos mais teóricos ou pesquisas de campo realizadas por outros pesquisadores. $\mathrm{E}$ também um rápido exercício rápido de registrar a reflexão de cada um e depois você comenta isso, isso varia muito de turma para turma, tem turmas mais pragmáticas e tem turmas que discutem melhor conceitos, fazem reflexões mais interessantes sobre aquilo que é aplicado na empresa, mas, por outro lado, eu também provoco, quando não é natural eu acabo chamando nominalmente, para saber o que a pessoa entendeu, como é na realidade dela, comentar.

Identificou-se durante as entrevistas a abordagem do professor que reflete sobre a teoria que envole sua prática docente. Neste contexto, o professor E salienta que o professor reflexivo é aquele "que reflete sobre sua aula, estabelecendo uma analise a partir da luz da teoria que sustenta o seu trabalho. Então, essa reflexão constante sobre teoria e prática docente". Para Rausch (2010), ser um professor reflexivo significa apropriar-se de teorias que fundamentam a docência, analisá-las, bem como refletir sobre o seu ensino e sobre as condições sociais a que pertence

Nesta mesma linha, merece destaque a definição do Professor I, que conceitua o professor reflexivo como "aquele professor que utiliza materiais de suas pesquisas e que tem reflexões sobre aquilo que está lendo, sobre o que está utilizando e não um professor que faz uma mera transmissão daquilo que aprendeu e as aulas serem sempre iguais". 
Esta compreensão retrata a importância do ato de ressignificar a sua prática docente. Para Castanho e Freitas (2006), é imprescindível o reconhecimento do professor bem como a sua valorização, portanto é necessário ressignificar os procedimentos educativos, admitindo a prática reflexiva. O professor E salienta que o professor reflexivo é aquele "que reflete sobre sua aula, estabelecendo uma análise a partir da luz da teoria que sustenta o seu trabalho. Então essa reflexão constante sobre teoria e prática docente”.

Dessa forma, Rausch (20I0), complementa que a formação de um profissional reflexivo é essencial para a autonomia no processo educacional, bem como a melhora na qualidade do ensino. Sendo assim o Professor B salienta que:

$\mathrm{Na}$ área da educação, tem me chamado muita atenção, uma área de pesquisa que procurar fazer com que os alunos tenham contato com a teoria (das diversas teorias) de uma forma mais lúdica, de uma forma que essa nova geração envolvida com tecnologia, tenha acesso à educação para nível de graduação de uma maneira diferente, que eu tive na minha graduação. Eu acho que na contabilidade a gente deveria colocar mais "peças educacionais" diferentes do que a gente utilizava antes. O aluno em sala de aula não está mais interessado em Power Point, em algo que fique congelado na tela, mas a inserção de vídeos, a inserção de materiais, até mesmo tirar o aluno do ambiente de sala de aula e levar para o ambiente externo, debaixo de uma árvore; talvez, essa maneira de fornecer o conhecimento seja mais absorvido pelos alunos. Eles acabam interagindo, a forma como isso tem ser apresentado deve estimular o julgamento, estimular a reflexão, isso eu acho interessante. Porque a gente não consegue treinar a reflexão, nessa história é preciso que façam uma leitura e discutam o assunto (PROFESSOR B).

Outro ponto que merece destaque é a aproximação dos conceitos de professor reflexivo e professor pesquisador, apesar de serem conceitos distintos. Conforme o Professor C, “o professor pesquisador está muito próximo do professor reflexivo, porque para chegar a um problema, para você investigar, já existe certa reflexão”. Dessa forma, Lüdke (2008) enfatiza 
que toda pesquisa ao ser realizada pelos professores tem um potencial de facilitar a prática reflexiva. Nesta linha de raciocínio, o Professor E afirma que existe

Há uma aproximação muito grande entre professor pesquisador e professor reflexivo, mas para mim são coisas distintas, embora uma dependa da outra. Então posso ser um professor reflexivo sem ser um professor pesquisador, sem desenvolver pesquisa, ou usar o método de pesquisa para construir conhecimento. Mas é difícil, ser um professor pesquisador, sem ser um professor reflexivo, porque automaticamente a pesquisa exige reflexão, exige a relação teoria/dado, teoria/prática. Ele como profissional se avalia permanentemente, se auto-analisa e se critica, então isso pode ocorrer pela autorreflexão, antes durante e depois da ação o que foi bom, o que poderia ter sido melhor, como os alunos interagiram no processo dinâmico, e também estabelecendo diálogos e processos avaliativos sobre a própria dinâmica das aulas, junto com os alunos (PROFESSOR E).

Isso vai ao encontro de Lüdke (2008), que ressalta que mesmo que a pesquisa e a reflexão sejam atividades distintas, estão diretamente relacionadas, pois estas são complementares e essenciais no processo de formação docente. A autora salienta que a reflexão é essencial no trabalho docente, e ainda afirma que se o professor é reflexivo, não significa que seja, além disso, pesquisador, logo todo o professor pesquisador precisa admitir uma posição reflexiva. Conforme Borg (20I0), ocorre uma distinção entre reflexão e pesquisa, enquanto que a pesquisa do professor visa ser reflexiva, a reflexão sobre a própria prática não se constitui necessariamente na pesquisa do professor.

Quanto ao questionamento das práticas adotadas na docência que evidenciam a perspectiva de professor reflexivo, o Professor $\mathrm{C}$ salientou que "na questão da reflexão, o professor não é o autor principal, ele será um mediador, ele vai instigar o aluno, vai criar pontes no debate, mas ele não pode ser o ator principal, pois os atores principais serão os alunos, e instigar isso é difícil". Complementa ainda que "o papel do professor é instigar isso e trazer textos, noticiários, mas o professor tem que ir atrás, para que o aluno perceba que aquele assunto é algo do dia a dia dele, caso contrário o aluno não cria esse interesse" (PROFESSOR C). As principais 
práticas apontadas pelos entrevistados portanto foram "a recomendação de textos bases que estejam voltados para esses campos de pesquisa, material para a condução da disciplina, o material já vem com essa característica de estímulo para que os alunos pesquisem dentro dessa área” (PROFESSOR G). Outra estratégia adotada descrita pelo Professor C é "adoção de debates de textos, de capítulos de livros, ou até mesmo de notícias relacionadas ao assunto”.

Sintetizando "a avaliação deve ser constante, a reflexão ocorre para a ação, na ação, sobre a ação, e a reflexão sobre a reflexão da ação” (PROFESSOR E). Schön (2000) salienta que essa é denominada a praxiologia para a reflexão, ou seja, as noções essências para que ocorra a reflexividade. Logo, o autor salienta que os profissionais reflexivos, refletem "na", "sobre” e "para a ação".

Finalizando, o professor reflexivo "é um professor essencial para a contabilidade nos dias de hoje; a contabilidade precisa formar alunos que tenham esse poder de julgamento, de raciocínio, de reflexão, sobre os eventos que vão ser controlados pela contabilidade” (PROFESSOR B), pois quando se trata de padronização contábil, harmonização das normas brasileiras às normas internacionais de contabilidade, o mercado exige a formação de um profissional preparado para superar estes desafios. Entretanto, os professores devem estar preparados para conviver neste ambiente de constantes mudanças na profissão docente (MONTEIRO, 2008). 


\section{CONSIDERAÇÕES FINAIS}

O objetivo do estudo foi analisar a compreensão dos professores do Programa de Pós Graduação de Ciências Contábeis sobre professor pesquisador e professor reflexivo na docência em nível stricto-sensu. Para atender ao objetivo, realizou-se uma pesquisa descritiva, com uma abordagem qualitativa dos dados obtidos com a realiacão de entrevistas com ro professores do Programa de Pós-Graduação em Ciências Contábeis (stricto-sensu), em uma universidade de Santa Catarina. A pesquisa foi realizada com os professores integrantes do programa cuja referência é o último trimestre de $201 \mathrm{I}$.

Foram verificadas as percepções quanto ao professor pesquisador e professor reflexivo, bem como as práticas adotadas na docência que evidenciam a perspectiva desses professores pesquisadores/reflexivos. Quanto à percepção de professor pesquisador elencada pelos entrevistados, vale ressaltar que no ponto de vista dos entrevistados, ele está preocupado não somente com o ensinar, mas inclusive com o pesquisar, permitindo que ocorra uma evolução do conhecimento. Logo o professor pesquisador assume um papel de mediador e não apenas de transmissor do conhecimento. Nesse sentido, André (2008) corrobora ao inferir que o professor pesquisador visa à valorização do papel social do professor como um agente de mudança e produtor de conhecimento.

As principais práticas adotadas na docência que evidenciam a perspectiva do professor pesquisador é a organização do trabalho em projetos de pesquisa, a incorporação da atitude de pesquisar entre os alunos e a pesquisa relacionada com a apresentação de seminários. Uma consideração apontada nas entrevistas seria a adoção de alunos bolsistas de iniciação cientifica. A participação em pesquisas possibilita ao aluno uma melhor preparação para ser um futuro pesquisador (LÜDKE, 2008).

Conclui-se que não existe um conceito bem definido para professor pesquisador. Dessa forma, identificaram-se quatro grupos de professores pesquisadores: a) os professores que somente realizam pesquisa; b) os 
professores que realizam pesquisa dentro de sua linha de pesquisa constituída ao longo do tempo; c) o professor que realiza pesquisa com seus alunos; e, por fim d) aquele professor que pensa sobre o que está pesquisando. Em suma, para os entrevistados, professor pesquisador é aquele que desenvolve pesquisa, com o intuito resolver problemas de questões que estão em debate, que pertençam a sua linha de pesquisa. A pesquisa visa à produção de conhecimento.

Na perspectiva da análise do professor reflexivo, os resultados, remetem para uma não uniformidade deste conceito, sendo eles classificados em quatro categorias: a) conceito indefinido de professor reflexivo; b) o professor que reflete sobre a teoria; c) o professor que reflete sobre a teoria que envolve sua prática docente, e d) a aproximação dos conceitos de professor reflexivo e professor pesquisador.

Dessa forma, cerca de $70 \%$ dos entrevistados demonstraram surpresa ao questionamento de sua percepção de professor reflexivo, ressaltando que não souberam de maneira imediata expressar algum conceito, sendo que, em alguns casos, esta havia sido a primeira vez que escutaram algum questionamento relacionado ao professor reflexivo.

O professor reflexivo é aquele capaz de regular a sua ação, desempenhando uma importante função na resolução de problemáticas da profissão docente; ele apresenta um método sistematizado de pensar sua docência.

Os resultados apontam para a importância da aproximação dos conceitos de professor pesquisador e professor reflexivo. Conforme Lüdke (2008), mesmo que sejam atividades distintas, elas são complementares e essenciais no processo de formação e atuação docente. A pesquisa efetuada pelos professores tem um potencial de facilitar a prática reflexiva, bem como reforçar a ligação entre teoria e prática.

Quanto às práticas adotadas na docência, que evidenciam a perspectiva do professor reflexivo dos pesquisados, percebe-se que o professor não é o autor principal, ele será um mediador, de modo a instigar o aluno a pesquisar. É necessário que os alunos tenham contato com as teorias de uma forma mais lúdica; vale destacar a recomendação de textos bases dentro da 
área e o debate de textos, de capítulos de livros, de notícias relacionadas ao assunto. Entretanto, a maioria dos entrevistados apontou aspectos voltados aos alunos e muito pouco aos aspectos de enisno, da docência em si

Conclui-se que a compreensão de professor reflexivo ainda não é consistente no stricto-sensu. Desse modo, surge a importância da educação continuada, para desenvolver principalmente esse processo de reflexão sobre as práticas adotadas por professores formados em diferentes áreas do conhecimento. .Muitos professores do stricto-sensu formam professores tendo pouca formação acerca dos saberes e fazeres docentes. A valorização da relação entre teoria e prática da docência tem importância na formação e atuação docente, pois ocorre o reconhecimento da experiência bem como da reflexão crítica para melhorar a prática e a importância do papel ativo do professor para promover a aprendizagem e o seu próprio desenvolvimento rofissional docente.

Recomenda-se para futuras pesquisas realizar uma reaplicação do estudo para outros programas de pós-graduação que possuam um foco maior na área da Educação. E como segunda recomendação, sugere-se a aplicação deste estudo com estudantes, no intuito de analisar as perspectivas de professor pesquisador e professor reflexivo na percepção de outros agentes, cuja finalidade seja analisar a importância dessa compreensão para a formação e atuação docente nos diferentes níveis e modalidades de ensino. 


\section{REFERÊNCIAS}

ALARCÃO, I. Professores reflexivos em uma escola reflexiva. 4.ed. São Paulo: Cortez, 2005. ANDRÉ, M. Pesquisa, Formação e Prática Docente. In: ANDRÉ, M. (Org.). O papel da pesquisa na formação e na prática dos professores. 8.ed. Campinas: Papirus, 2008, p. 55-69.

BORG, S. Language teacher research engagement. Cambridge Journals, v. 43, n. 4, p. 391429, 2010.

CASTANHO, D.; FREITAS, S. N. Inclusão e prática docente no ensino superior. Educação Especial, n. 27, 2006.

CHARLOT, B. Formação de professores: a pesquisa e a política educacional. In: PIMENTA, S.G.; GHEDIN, E. (Org.). Professor reflexivo no Brasil: gênese e critica de um conceito. 2.ed. São Paulo: Cortez, 2002, p. 89-108.

FONTANA, M.I. A prática de pesquisa: relação teoria e prática no curso de Pedagogia. Curitiba, 2006. 167f. Dissertação (Mestrado em Pedagogia) - Programa de PósGraduação em Educação da Pontifícia Universidade Católica do Paraná, Curitiba.

FREITAS, H.; JANISSEK, R. Análise Léxica e Análise de Conteúdo: técnicas complementares, sequenciais e recorrentes para exploração de dados qualitativos. Porto Alegre: Editora Sagra Luzzatto, 2000.

LÜDKE, M. A complexa relação entre o professor e a pesquisa. In: ANDRÉ, M. (Org.). O papel da pesquisa na formação e na prática dos professores. 8.ed. Campinas: Papirus, 2008, p. $27-55$.

MIRANDA, M. G. de. O professor pesquisador e sua pretensão de resolver a relação entre teoria e a prática na formação de professores. In: ANDRÉ, M. (Org.). O papel da pesquisa na formação e na prática dos professores. 8.ed. Campinas: Papirus, 2008. p. 129-143.

MONTEIRO, C. C. D. A construção de uma escola reflexiva. Estudo de caso: Escola Secundária de Achada Grande. 2008. 99f. Memória Monográfica. Universidade Jean Piaget de Cabo Verde. Cabo Verde, 2008.

NUNES, D.R.P. Teoria, pesquisa e prática em Educação: a formação do professorpesquisador. Educação e Pesquisa, v. 34, n. 1, p. 97-107, 2007.

RAUSCH, R.B. Reflexividade e pesquisa: articulação necessária na formação inicial de professores. In: SILVA, N. de M. A.; RAUSCH, R. B. (Orgs.). Formação de professores: políticas, gestão e práticas. Blumenau: Edifurb, 2010.

SÁ-CHAVES, I. Portfolios Reflexivos. Estratégia de Formação e de Supervisão. Aveiro: Universidade de Aveiro (CIDTFF), 2000.

SÁ-CHAVES, I. A Construção de Conhecimento pela Análise Reflexiva da Praxis. Lisboa: Fundação para a Ciência e a Tecnologia/Fundação Calouste Gulbenkian, 2002.

SCHÖN, D. A. Educando o profissional reflexivo: um novo design para o ensino e a aprendizagem. Tradução de Roberto Cataldo Costa. Porto Alegre: ARTMED, 2000. 
STENHOUSE, L. An introduction to curriculum research and development. Londres: Heinemann, 1975.

ZEICHNER, K.M. Para além da divisão entre professor-pesquisador e pesquisador acadêmico In: GERALDI, C.M.; FIORENTINI, D.; PEREIRA, E.M. (Orgs.). Cartografia do trabalho docente: professor(a)-pesquisador(a). Campinas: ABL, 1998, p. 207-236. 


\section{DADOS DOS AUTORES}

FERNANDA KREUZBERG` fernandakreuzberg@gmail.com Mestranda em Ciências Contábeis pela FURB

Instituição de vinculação: Universidade Regional de Blumenau Blumenau/SC - Brasil

Áreas de interesse em pesquisa: Contabilidade Financeira, Contabilidade Internacional e Usuário Externo.

* Rua Antônio da Veiga, 146 Vila Nova 89000-140 Blumenau/SC

\section{RITA BUZZI RAUSCH ritabuzzirausch@gmail.com}

Doutora em Educação pela UNICAMP

Instituição de vinculação: Universidade Regional de Blumenau Blumenau/SC - Brasil

Áreas de interesse em pesquisa: Formação inicial e contínua de professores e aos saberes docentes. 